\title{
Loja capital musical del Ecuador Loja musical capital of Ecuador
}

\author{
María Eugenia Rodríguez Guerrero*, Manuel Lizardo Tusa Tusa ${ }^{\dagger}$ \\ Universidad Nacional de Loja, Ecuador. \\ maria.rodriguezg@unl.edu.ec,lizardotusa26@yahoo.es
}

Fecha de recepción: 29 de octubre de 2016 - Fecha de aceptación: 22 de noviembre de 2016

\begin{abstract}
Resumen-En el argot de los lojanos, se dice que Loja es la capital musical de Ecuador, tesis o cliché, lo que ha llevado a escribir el presente artículo para encontrar el sustento empírico teórico y prácticas que la sustenten, constituyéndolo en objeto de investigación y recomendar a futuro las innovaciones que es necesario introducir en aras a sostener y potenciar este sitial de Loja. Esta primera aproximación tiene como problema ¿Qué posee Loja, que la diferencia del resto de las provincias del Ecuador en el campo musical, para ser considerada su capital? Esta primera entrega tiene por objetivo construir un marco de conceptos ordenadores que abran en la posteridad un campo de investigaciones sobre la música y que se traduzcan en políticas, planes programas y proyectos que la potencien. Se desarrollan tres conceptos ordenadores derivados de la tesis: el poder construir música que hace referencia a las competencias genéricas y específicas en distintos instrumentos y géneros, la cantidad de música que se produce y el talento humano en formación musical, que se desarrolla en Loja. Se recoge evidencia empírica para corroborar o rechazar la hipótesis: Loja es capital musical del Ecuador. Se recogen datos sobre las competencias musicales y se compara a nivel mundial, igual de las productoras musicales y escenarios de formación en música. Al final se comprueba la hipótesis. La tarea de los lojanos es innovar la capital.
\end{abstract}

Palabras Clave-Música, competencias musicales, talento musical en formación, cantidad de música, interpretación musical, instrumento musical, canciones.

\begin{abstract}
In the slang language of Lojanos, it is said that Loja is the musical capital of Ecuador. thesis or cliché, which has led to write the present article to find the theoretical empirical support and practices that support it, constituting it in research object and recommend to the future the innovations that need to be introduced in order to sustain and strengthen this place of Loja. This first approach has as a problem What does Loja provides, that distinguish from the rest of the provinces of Ecuador in the musical field, to be considered its capital? This first delivery aims to build a framework of computer concepts that open up posterity to a field of research on music and that translate into policies, plans and programs that empower it. They develop three concepts derived from the thesis: the power to construct music that refers to the generic and specific competences in different instruments and genres, the amount of music that is produced and the human talent in musical formation that is developed in Loja. Empirical evidence is collected to corroborate or reject the hypothesis: Loja is the musical capital of Ecuador. Data are collected on musical skills and compared at the global level, as well as music production and music training scenarios. At the end the hypothesis is checked. The task of the Lojanos is to innovate the capital. Keywords: Music, musical competitions, musical talent in training, amount of music, musicalperformance, musical instrument, songs.
\end{abstract}

Keywords-Music, musical competitions, musical talent in training, amount of music, musicalperformance, musical instrument, songs.

\section{INTRODUCCIÓN}

$\mathbf{E}$ 1 contexto de justificación del artículo está dado por las nuevas políticas que el estado tiene sobre cultura, arte y música para que tengan en el Ecuador remembranza, también porque se ha centralizado la producción del arte en Guayaquil con la Universidad de las Artes, cuando realmente los lojanos esperaban un trato preferencial por considerarse que Loja es la cuna de la música. Entonces surge la idea de crear conceptos científicos para estudiar lo que en investigaciones como de Cabrera Guaman (2016), y de JARAMILLO and RENÉ (2013) que concluyen en la necesidad de investigar el capital musical de Loja.

El problema de análisis es ¿Qué posee Loja, que la diferencia del resto de las provincias del Ecuador en el campo musical, para ser considerada su capital?, de donde se derivan

\footnotetext{
*Licenciada en Psicología Infantil y Educación Parvularia, Magister en Educación y Desarrollo Social

${ }^{\dagger}$ Licenciado en Físico Matemáticas, Magíster en Docencia Universitaria e Investigación Educativa
}

tres sub problemas: ¿qué competencias genéricas y especificas en distintos instrumentos y géneros se desempeñan?, ¿Cuál es la cantidad de música que se produce? y ¿cómo se forma el talento musical?

Como objetivo general se plantea analizar por qué Loja es considerada la capital musical del Ecuador y como objetivos específicos: determinar las competencias musicales de conocimiento y desempeño, inferir la cantidad de música que se produce cada año y caracterizar las instituciones, grados y niveles de formación de talentos musicales.

El impacto que tiene para la comunidad científica es generar datos y conceptos ordenadores para posteriores investigaciones, porque al momento hay un estado del arte muy incipiente en materia de investigación musical, pero lo que interesa es investigar este sitial de alto prestigio para que los organismos de gobierno local y provincial agreguen al régimen de desarrollo a la música como bien económico, político y cultural.

La metodología empleada para desarrollar el artículo consideró los siguientes aspectos:

Hipotética deductiva, parte de una tesis, se determinan 
las premisas, el análisis teórico de cada una, se derivan las preguntas de indagación de campo, con el planteamiento de la hipótesis, se elabora un marco teórico empírico, construyen resultados, se discute y finalmente se llega a conclusiones y recomendaciones.

Para visibilizar esta realidad se sistematiza datos estadísticos concernientes a tres fuentes: el poder musical que tiene Loja en el contexto del país; la cantidad de música que se viene generando en el presente siglo y el talento humano en proceso de formación musical en la provincia. Con esta información se crearán políticas, planes, programas y proyectos estatales y provinciales para capitalizar un marco de profesiones que en conjunto potencien la economía del conocimiento musical.

El poder musical que tiene Loja teóricamente hace relación al poder hacer música, con un significado de competencia, en palabras de Sergio (2006), se la concibe como"procesos complejos de desempeño con idoneidad en un determinado contexto, con responsabilidad", el análisis teórico va enfocado en la dirección de este hilo conductor especificando significados sobre los términos procesos, complejos, desempeño, idoneidad, contextos y responsabilidad, al tiempo que son conceptos que facilitan la obtención de información sobre el desarrollo de la música.

La categoría cantidad de música tiene relación con la producción musical inédita, interpretada y recreada que se ha dado en el presente siglo. Y finalmente la categoría talento musical en formación, cuantifica el número de personas que están estudiando música en sus diversas manifestaciones en el periodo 2000-2016. Se desconoce información puntual que verifique la hipótesis de que Loja es capital musical del Ecuador e incluso se carece de información relevante que confirme o niegue esta idea, existiendo controversias sobre la certeza de que esta provincia tenga tan honroso título.

El estudio se da en un contexto en donde se magnifica al ser humano como sujeto histórico social posesionado de visiones teórico prácticas para construir su proyecto de vida, es evidente que la dimensión musical tiene un lugar protagónico en la construcción de tal condición humana. No quiere decir con ello que es a partir de la nueva Constitución que se incrementa el pensamiento musical en Loja, en otros momentos y con otras constituciones se avanzó con gran dinamismo, por esta razón es que se hacen tres tipos de estudios para demostrar que Loja es capital musical del Ecuador, a saber que competencias complejas musicales se han desarrollado y desarrollan en esta ciudad; la cantidad de música que se ha generado en el periodo comprendido entre 2000 a 2016 y el talento musical en formación. El artículo está estructurado de la siguiente manera: título, autores, resumen, cuerpo del artículo, discusión, conclusiones recomendaciones y bibliografía.

\section{Metodología}

Para la realización del trabajo de investigación se utilizó el siguiente proceso metodológico que se detalla a continuación:

\section{Diseño de investigación}

La investigación es hipotética deductiva. A partir de la hipótesis: Loja es capital musical del Ecuador, se desprenden las siguientes categorías de análisis: El poder musical que tiene Loja en el contexto del país; la cantidad de música que se genera en Loja; y el talento musical en formación en Loja.

Los datos referidos al poder hacer música en Loja se han obtenido del análisis de las competencias genéricas y específicas, grupales e individuales de las personas que hacen música.

Para analizar la cantidad de música que se genera en Loja se ha realizado una aproximación al número de canciones que se producen al año tomando como referente la cohorte 2000 - 2016 información proporcionada por los estudios de grabación conocidos en la ciudad. La información sobre el talento musical se la obtiene de los datos proporcionados por los centros más importantes que forman músicos en la cohorte 2000-2016.

El universo de estudio, está constituido por 5000 músicos y un estimado de 20000 canciones en la cohorte de tiempo 2000-2016.

Para el estudio del poder musical en Loja, se tomó como punto de partida el concepto de competencia, que abarca el conocer y el saber hacer música; así un violinista tiene a su haber un conjunto de competencias genéricas y específicas que le dan esta categoría: Interpreta música como competencia genérica y como competencias específicas interpreta música nacional, folklórica, popular, clásica, barroca, etc.

En el estudio del talento musical se utilizó la técnica descriptiva en base a la información proporcionada por los centros educativos sobre la cantidad de músicos graduados en los centros educativos de Loja.

En relación a la cantidad de música que produce en Loja, se acudió a los archivos de los centros de grabación que al momento tiene Loja.

Se hizo un sondeo de opinión a manera de censo para recoger información empírica pertinente y sistematizarla.

El análisis de los datos se ha realizado en base a tres aspectos:

- La conceptualización de la variable.

- Cuantificación de la variable

- Interpretación de la variable

a. Metodología para determinar el poder musical que tiene Loja El poder hacer música en Loja está visibilizado por las competencias genéricas y específicas, grupales e individuales, de informantes que hacen música en Loja.

b. Metodología para obtener la cantidad de música que se genera en Loja Este criterio se cuantifica por el número de canciones que se producen al año en Loja, tomando como referente la cohorte 2000-2016, para lo cual se considera como fuentes de información e informantes que graban música y la distribuyen.

c. Metodología para determinar el talento musical en formación en Loja En la cohorte 2000-2016 la formación del talento musical ha tenido que atravesar por dos normativas: antes del 2011 y posterior a esta fecha; considerando esta situación la formación del talento musical en Loja, la realizan instituciones como Conservatorio Superior de Música Salvador Bustamante Celi, Conservatorio Antón Bruckner y Carrera de Educación Musical de la Universidad Nacional de Loja. 


\section{Antecedentes}

Según Cabrera Guaman (2016), en su trabajo de investigación acerca de la música inédita de los egresados de la carrera de educación musical de la universidad Nacional de Loja y contribuir con la producción musical de la ciudad, concluye que es muy importante recopilar las canciones inéditas infantil y poder difundir esta música para los niños para coadyuvar en el desarrollo musical de Loja.

Gualán and Frías (2015) en su tesis titulada la ejecución de la música ecuatoriana en el fortalecimiento de la identidad cultural de los niños, manifiestan que ha logrado descubrir la riqueza cultural de la música ecuatoriana, fomentando en los alumnos y maestros la apreciación de los ritmos tradicionales.

JARAMILLO and RENÉ (2013), en la investigación sobre la creación artística de los jóvenes compositores lojanos y su incidencia en el desarrollo artístico-cultural de Loja, manifiesta en uno de sus objetivos ofrecer una recopilación de obras artísticas de los jóvenes compositores lojanos que contribuyen al desarrollo de la ciudad, para lograr el conocimiento de las composiciones lojanas de los compositores de los últimos diez años.

\section{El poder musical}

El poder hacer música se define como el conjunto de competencias genéricas y específicas que se desarrollan en Loja en el campo musical. Holísticamente una competencia es un proceso complejo de desempeño humano en el ámbito de la música, con determinados niveles de idoneidad para responder a carencias y/o necesidades de un contexto social determinado, y que por la misma razón social, tiene que desarrollarse con responsabilidad.

López (2012), al referirse a las competencias musicales genéricas básicas las señala como expresión musical, que sepa cantar; creatividad musical, uso de materiales para crear música; perceptiva musical, experimentación con diferentes niveles de percepción musical; competencia musicológica, conceptualización de la terminología musical; e instrumental, autoconciencia de la relación teoría-práctica musical.

Las competencias específicas son haceres particulares en el campo de la música que se erigen sobre la base de las genéricas. Son específicas las siguientes:

\section{Ámbito Cuerdas}

En cuerdas frotadas: violinistas, violistas, violoncelistas, y contrabajistas En cuerdas punteadas: guitarristas, bandolonistas, banjoistas, lauditas, arpistas, clavecinistas, citaristas. En cuerda golpeada: cimbalistas, clavicordioistas y pianistas.

\section{Ámbito Vientos}

Soplo Humano, madera, embocadura: flautistas, flautinistas. Soplo humano, madera, embocadura doble, lengüeta doble: oboístas, cornistas, fagotistas, contrafagotistas.

Soplo humano, madera, embocadura doble, lengüeta simple: clarinetistas, saxistas. Soplo humano, metal: cornetistas, fliscornistas, trompetistas, trompistas, trombonistas, tubistas, bombardinistas, sousaphonistas.

Soplo mecánico: organistas, armonistas, acordeonistas. Ámbito Percusión
Sonido Determinado: timbalistas. Xilofonistas. Sonido Indeterminado, membranas: tamborilero, otros (caja clara, pandereta y bombo) Sonido Indeterminado, Metal: platilleros otros (crótalos, gong, triángulo, sistro) Sonido indeterminado, madera: castañuelistas, otros (matraca, caja china, maracas, claves, látigo, güiro.

\section{Ámbito Instrumentos folklóricos latinoamenricanos}

Aerófonos: quena, quenacho, tarka, ocarina, mohseño, trutruka. Zampoña, rondador, pifilka, pututo. Cordófonos Charango, ronroco, chillador, mandolina, tiple, cuatro venezolano, cuatro puertorriqueño, guitarra, bajo eléctrico, bajuela mexicana. Membranófonos: bombolegüero, kultrún, bongó. Ideófonos: cajón peruano, trompe, huiro, marimba.

\section{La cantidad de música}

La cantidad de música se define como el número de canciones inéditas, imitadas o arregladas, en diferentes géneros que se diseñan en los estudios de grabación, o que se producenpor iniciativa de las personalidades musicales; aquella que se encuentran codificadas en los museos de la música; la registrada en las asociaciones de profesionales músicos y la producción musical que está inscripta en el instituto ecuatoriano de propiedad intelectual.

\section{El Talento Musical en formación}

Según Gardner and Nogués (2011), el talento musical lleva intrínseco una particular inteligencia, que la codificó en su teoría de las inteligencias múltiples, expuso sus características indicando que es la capacidad musical que incluye habilidades en el canto dentro de cualquier tecnicismo y género,tocar un instrumento a la perfección y lograr con él una adecuada presentación, dirigir un conjunto, ensamble, orquesta; componer (en cualquier modo y género) y tener apreciación musical.Componer e interpretar piezas con tono, ritmo y timbre en sí, escuchar y juzgar eficazmente tanto la música como el sonido en general. La inteligencia musical también se hace evidente en el desarrollo lingüístico, por cuanto demanda del individuo procesos mentales que involucran la categorización de referencias auditivas y su posterior asociación con preconceptos; esto es, el desarrollo de una habilidad para retener estructuras lingüísticas y asimilarlas en sus realizaciones fonéticas.

Consecuentemente el talento musical se forma, es una potencialidad, para convertirse en capacidad, requiere de centros de formación académica, con objetivos de aprendizaje musicales que articulan efectividad, eficacia, planificación, legislación y participación.

\section{RESUltados}

\section{El poder musical de Loja}

Los dominios competenciales que tiene Loja en producción musical corresponden a las agrupaciones y a personalidades con impacto social en el campo de la música en Loja y fuera de ella. En relación a las agrupaciones las competencias que se generan tienen un campo de aplicación diverso, según sea la modalidad. 


\section{Modalidad Orquesta Sinfónica}

En esta modalidad tienen sitial indiscutible la Orquesta Sinfónica de Loja, Orquesta Sinfónica Municipal, Orquesta Filarmónica Universitaria, Orquesta SINFÍN de la Universidad Técnica Particular de Loja, Orquesta Juvenil del Conservatorio Salvador Bustamante Celi.

\section{Orquesta Popular}

esta modalidad destacan agrupaciones con mucho éxito, es el caso de Candomblé, Sabe a Kaña, Rumba Caliente, Kaoba, Los Niches, Don Medardo y sus Players.

\section{Banda de Música}

Es una tradicional forma de agruparse de los músicos de Loja, corresponden a pueblos o barrios, e instituciones, entre las más importantes están: Show Alma Lojana, Jesús del Gran Poder Loja, Ecuador, Dios Patria, Banda de la Policía de Loja, San Francisco, Taquil, San Vicente, Santiago, 24 de Junio, Gualel, Banda de la Sociedad de Obreros de Loja, Reina del Cisne, Loja y San Pedro de la Bendita.

\section{Banda de Jazz}

Esta es una modalidad que no falta en Loja, agrupa jóvenes de diferentes edades, entre las más sobresalientes se distinguen Brasil Jazz, Villonaco, A Jazz Record Mart.

\section{Modalidad Coros}

Este tipo de agrupación está altamente desarrollado en Loja, la tendencia de organización corresponde a las instituciones especialmente educativas quienes vienen haciendo encuentros de trascendencia. Esta modalidad tiene a sus principales representantes en los grupos corales como: Universidad Técnica Particular de Loja, Universidad Nacional de Loja, Consejo Provincial de Loja, Conservatorio de Música Salvador Bustamante Celi, instituciones educativas, Unión de Mujeres Lojanas, coros de las iglesias, parroquias y cantones.

\section{Modalidad Círculos Musicales}

Modalidad representada por una gran riqueza orgánica, funcionando en diferentes tipos de grupos musicales que van desde, duos, tríos, cuartetos, quintetos, sextetos, grupos de cámara. Destacan: Semblanzas, Madera dorada, Madrigal, Hermanos Rodríguez, Zcardas, Cuerdas Lojanas, Grupo de cuerdas de la Orquesta sinfónica de Loja, grupo de cuerdas del Conservatorio Salvador Bustamante Celi, Grupo de Guitarras del Conservatorio Salvador BustamenteCeli, Contrapunto, H. Consejo provincial de Loja, H. Municipio de Loja y Sinamune.

\section{Personalidades que han aportado a crear música en Loja}

En este apartado se ubican a las personas que con su arte musical convierten a Loja en un ícono del pensamiento y práctica musical del Ecuador. Su impacto no es sólo es local sino nacional e internacional, de ahí que forman parte de la cultura ecuatoriana y de obligada consulta de las generaciones de músicos que incursionan en este arte. Se agrega un conjunto de talentos musicales creadores de la identidad musical de Loja (Tablas 1 y 2).

Agrupaciones y personalidades que han trabajado en base a competencias musicales demostrando conocimiento y creatividad para la producción musical. Los desempeños que han tenido la oportunidad de impulsarlos en Loja, se los puede encontrar en cualquier parte del mundo, lo cual demuestra su poder musical de primera categoría. Entre las competencias se cuentan a las siguientes:

\section{Competencias a nivel de agrupaciones musicales}

Violinistas, violistas, chelistas, bajistas, flautistas, oboístas, clarinetistas, saxistas, cornistas, trompetistas, trombonistas, fagotistas, percusionistas, timbales, pianista, arpista (Tabla 3).

\section{Competencias de las personalidades musicales}

Cantantes, autores, compositores, arreglista, director de orquesta, grupo de cámara y/o coros, sonidistas, maestros de capilla, profesores de música, pedagogos musicales, instrumentistas.

Luego de la entrevista a los centros de grabación de música que operan en Loja (Chavi Records, Wilman Palacios, Boris Eguiguren, Los Lozano, Roque Pineda) y tomando archivos que van del 2000-2016, se estarían grabando alrededor de 20000 canciones en esta cohorte, lo que da lugar a pensar que en un año se producen 1250 canciones, cifra que en ninguna ciudad del Ecuador alcanza tales niveles (Tabla 4).

\section{Talento musical en formación en Loja}

El talento musical está constituido por las personas que se han graduado de las instituciones educativas de Loja con un total de 3661 profesionales del Conservatorio Salvador BustamenteCeli, Antón Bruckner, y la Carrera de Educación Musical de la Universidad Nacional de Loja esta cifra supera al resto de provincias del Ecuador cuyos índices son muy inferiores a pesar de que su población es mayor (Tablas 5, 6 y 7$)$

\section{DISCUSIÓN}

De las múltiples competencias musicales, empezando desde las más simples a las más complejas son desarrolladas por músicos lojanos, cuestión que coincide con el trabajo realizado por JARAMILLO and RENÉ (2013), donde se conoce la importancia de recopilar las composiciones lojanas de los últimos diez años para reconocer la cultura de la ciudad de Loja. En donde se llega a concluir que la mayoría de las competencias musicales que hay en el mundo, los músicos lojanos las desarrollan dirigiendo y organizando orquestas, componiendo obras musicales, ejecutando instrumentos con destreza y perfección como el caso de Manfred Mora Cel, virtuoso pianista que actualmente radica en Alemania y ha compartido su genialidad musical en diversos países y ciudades que gustan de la música.

La producción musical un objeto que está en construcción porque se carece de investigaciones dedicadas a determinar el potencial musical de Loja en cuanto a producción, edición y mercadeo de canciones musicales que se editan en un determinado tiempo. La información que se tiene corresponde al momento y escasea datos vinculados con la producción 
Tabla 1. Músicos relevantes en la historia de Loja - Primera Generación.

\begin{tabular}{|c|c|c|c|}
\hline No & Nombres y Apellidos & Obras & Instrumento \\
\hline 1 & Salvador Bustamante Celi & $\begin{array}{l}\text { Pensil Lojano } \\
\text { Angélica } \\
\text { Lucerito } \\
\text { Himno a Loja } \\
\text { La morita } \\
\text { Los adioses }\end{array}$ & Piano \\
\hline 2 & Marcos Ochoa Muñoz & La Flor Zamorana & Piano \\
\hline 3 & Manuel de Jesús Lozano & $\begin{array}{l}\text { Ya no te quiero } \\
\text { pero no te olvido } \\
\text { Porqué } \\
\text { Cuando siente } \\
\text { el corazón } \\
\text { Mónica Elizabeth }\end{array}$ & Piano \\
\hline 4 & Francisco Rodas Bustamante & & Piano \\
\hline 5 & Segundo Puertas Moreno & Alma de bohemio & Guitarra \\
\hline 6 & Segundo Cueva Celi & $\begin{array}{l}\text { Pequeña ciudadana } \\
\text { Vaso de Lágrimas }\end{array}$ & Piano \\
\hline 7 & David Pacheco Ochoa & Ninfa de Luz & Piano \\
\hline 8 & Cristóbal Ojeda Dávila & Penas Mías & Piano \\
\hline 9 & Armengol Barba & Idolatría & Piano \\
\hline 10 & Estanislao Pesantes & $\begin{array}{l}\text { Cumandá } \\
\text { Separación } \\
\text { A mi madre }\end{array}$ & Piano \\
\hline
\end{tabular}

Fuente: Rodríguez, Pineda, Mora (2015) Nuestro Ecuador en Notas.

musical generada en la actualidad o en épocas pasadas. Hay mucha producción musical que aún permanece en estado oculto, no es editada por una serie de carencias en las que priman la falta de desarrollo tecnológico y económico.

La formación del talento humano en música es definitivamente diferente en relación con otras provincias. Cada año tan sólo en uno de los conservatorio del estado Salvador Bustamente Celi, ingresan demostrando actitudes musicales de 1500 a 2000 niños que frisan los siete años de vida; lo que visibiliza el carácter y la pasión del lojano por hacer de la música su bastión de identidad. En comparación con otras ciudades del Ecuador, Loja supera en gran medida en cuanto a número de personas graduadas en el campo de la música. Este proceso de perfección es atípico de los lojanos. No sólo que se toma la formación musical como una profesión, hay circunstancias en las cuales las personas que se forman para ser músicos incursionan en el tejido social desde sus competencias y de otras como profesionales: arquitectos músicos, profesores músicos, ingenieros músicos, médicos músicos, abogados músicos.

\section{Conclusiones}

El poder musical de Loja, es probablemente integral, reúne competencias genéricas y específicas que la musicología a nivel internacional ha desarrollado como campo de estudio y trabajo que la ubican en el sitial de ser capital musical del Ecuador. La cantidad de música que se genera en Loja es mayor que todas las provincias, tiene un nivel de aproximadamente 20000 canciones por año entre inéditas, imitadas o arregladas, potencial que la transforma en capital musical del Ecuador.

El talento musical en vías de formación en instituciones, niveles y carreras universitarias supera para el presente año en 1500 estudiosos de la música, una cifra que resulta inalcanzable para otras provincias, ratificando que Loja es capital musical del Ecuador.

\section{RECOMENDACIONES}

A los gobiernos parroquiales, cantonales y provinciales, para que ubiquen como política de desarrollo y conste en los planes, programas y proyectos, al nivel que corresponden la organización de sociedades de producción de música, integrando interdisciplinariamente varias competencias musicales, en la forma de asociaciones, orquestas, grupos, bandas, coros, tríos, dúos, etc., para aprovechar las competencias musicales que se encuentras dispersas y contar con espacios sociales para captar oportunidades de trabajo como músicos y complementariamente la apertura de espacios para perfeccionar y actualizar las competencias. Al ministerio de cultura la implementación de centros de producción y grabación de música, accesibles a las condiciones socio económicas del músico.

Integrar el sistema de educación musical de Loja de tal manera que haya un nivel básico de descubrimiento del talento musical, luego la formación, grado y post grado universitario, para que Loja no solo que exporte producción musical sino talentos musicales.

\section{REFERENCIAS BIBLIOGRÁFICAS}

Cabrera Guaman, M. H. (2016). La música inédita de los estudiantes egresados de la carrera de educación musical de la universidad nacional de loja promoción 2014, en el proceso de enseñanza-aprendizaje de los estudiantes del 1er. año de educación básica de la escuela zoila maría astudillo celi de la ciudad de loja. periodo 2015. B.S. thesis.

Gardner, H. and Nogués, M. T. M. (2011). Inteligencias múltiples. Paidós.

Gualán, W. R. A. and Frías, V. F. P. (2015). "la ejecución de la música ecuatoriana en el fortalecimiento de la identidad cultural de los niños y niñas del 5 to año de educación básica de la escuela lauro damerval ayora $n^{\circ} 2$ de la ciudad de loja en el periodo 2013-2014”. 
JARAMILLO, P. and RENÉ, W. (2013). La creación artística de los jóvenes compositores lojanos y su incidencia en el desarrollo artístico-cultural de la ciudad de loja. periodo 2000-2010.

López, N. (2012). Competencias musicales básicas.

Sergio, T. (2006). Aspectos básicos de la formación basada en competencias. Talca, Proyecto Mesesup. 
Tabla 2. Músicos relevantes en la historia de Loja - Segunda Generación.

\begin{tabular}{|c|c|c|c|}
\hline No & Nombres y Apellidos & Obras & Instrumento \\
\hline 1 & Juan Gordón Ureña & El valor de tenerte & Guitarra \\
\hline 2 & Emilio A. Jaramillo & Eres mi ensueño & Guitarra \\
\hline 3 & Luzuriaga Medardo & Loja castellana & Guitarra \\
\hline 4 & Tulio Bustos & $\begin{array}{l}\text { El negro } \\
\text { Alejandro ha muerto } \\
\text { Muñequita } \\
\text { Tu } \\
\text { mirar }\end{array}$ & Guitarra \\
\hline 5 & Dans Dagoberto Vilela & Nostalgia & Guitarra \\
\hline 6 & Segundo Puertas Moreno & Alma de bohemio & Guitarra \\
\hline 7 & Mélida María Jaramillo Rodríguez & Intérprete & Voz \\
\hline 8 & Benjamín, el gato Ortega & Loja en mi país & Guitarra y voz \\
\hline 9 & Carlos M Valarezo F & Dulce amor mío & Piano \\
\hline 10 & Edgar Augusto Palacios & $\begin{array}{l}\text { Madre } \\
\text { Lo que no vendrá } \\
\text { Guayaquil } \\
\text { Tú } \\
\text { A la luz } \\
\text { de la luna } \\
\text { Amor mío } \\
\text { Boletín y elegía de las mitas }\end{array}$ & Trompeta \\
\hline 11 & Don Medardo y sus Players & $\begin{array}{l}\text { El Aguajal } \\
\text { El Aguacerito }\end{array}$ & Piano \\
\hline 12 & César Alberto Ortega & $\begin{array}{l}\text { Lojanita consentida } \\
\text { Siempre jovial } \\
\text { Tierrita de } \\
\text { mis amores } \\
\text { Llora y ríe corazón } \\
\text { Todos }\end{array}$ & Piano \\
\hline 13 & Santiago Erráez & Corazón & Voz \\
\hline 14 & Trosky Guerrero & $\begin{array}{l}\text { Añoranzas y tradiciones de mi lindo Catacocha } \\
\text { Lo que hice por tí }\end{array}$ & Guitarra y voz \\
\hline 15 & Hernán Sotomayor & A tajitos de caña & Guitarra y voz \\
\hline 16 & Roque Pineda Albán & $\begin{array}{l}\text { Desamor } \\
\text { Ecuador Profundo } \\
\text { El campo } \\
\text { Lindo es mi Quilanga } \\
\text { Nuestra Tierra } \\
\text { Piano dile } \\
\text { que vuelva } \\
\text { Pienso en ti }\end{array}$ & Piano \\
\hline 17 & Alcívar Ortiz & Promesas & Guitarra \\
\hline 18 & Anthony Calva & $\begin{array}{l}\text { La fiesta } \\
\text { Recordarte }\end{array}$ & Piano \\
\hline 19 & José Aníbal Pucha & $\begin{array}{l}\text { Tonada para Jossué } \\
\text { Sal de inmediato a buscarte } \\
\text { Eternamente mujer } \\
\text { Señora del Cisne }\end{array}$ & Flauta \\
\hline 20 & Oswaldo Mora Rivas & $\begin{array}{l}\text { Intérprete } \\
\text { Tenor }\end{array}$ & Voz, fagot \\
\hline 21 & Raúl Mora Rivas & $\begin{array}{l}\text { María Elena } \\
\text { Receta para el corazón }\end{array}$ & Violín, voz \\
\hline 22 & Edgar Ludeña & Agustín Emilio & Voz \\
\hline 23 & Felipe Huiracocha & $\begin{array}{l}\text { Aji de Cuy } \\
\text { Chasito Lojano }\end{array}$ & Clarinete, saxo \\
\hline 24 & María Eugenia Rodríguez Guerrero & Aniversario & Violín \\
\hline 25 & Benjamín Aguilera & Chagrita Caprichosa & Piano \\
\hline 26 & Víctor de Veintimilla & Chamiza & Piano \\
\hline 27 & Ketty Moreno & $\begin{array}{l}\text { Me acordé de tí } \\
\text { Te voy a dejar vivir } \\
\text { De todos } \\
\text { mis amores }\end{array}$ & Voz \\
\hline 28 & José Pío Ruilova & $\begin{array}{l}\text { Día del Jubilado } \\
\text { La música } \\
\text { María José }\end{array}$ & Piano, bajo \\
\hline 29 & Edgar Ludeña & Marieta Eterna & Guitarra \\
\hline 30 & Miguel Rojas & Mi último adiós & Guitarra \\
\hline 31 & Marlon Arias & Pueblito mío & Piano \\
\hline 32 & Hítalo Coello & Soy de ti & Piano \\
\hline 33 & Carlos Alberto Ortega Salinas & $\begin{array}{l}\text { Nuestra Patria } \\
\text { Mi pueblito } \\
\text { Cuando yo } \\
\text { despierto } \\
\text { La feria }\end{array}$ & Flauta, piano \\
\hline
\end{tabular}

Fuente: Rodríguez, Pineda, Mora (2015) Nuestro Ecuador en Notas. 
Tabla 3. Músicos Instrumentistas - Segunda Generación

\begin{tabular}{|c|c|c|}
\hline $\mathbf{N}$ & Nombres y Apellidos & Obras \\
\hline 1 & Jorge Serrano Valdivieso & Intérprete, arreglista \\
\hline 2 & Blanca Padilla & Intérprete, arreglista \\
\hline 3 & César y Carlos Rodríguez & Intérpretes \\
\hline 4 & Guillermo Espinoza Espejo & Piano \\
\hline 5 & Rocío Espinoza & Intérprete \\
\hline 6 & Guillermo Espinoza & Intérprete \\
\hline 7 & Wilmer Huiracocha & Instrumentista, arreglista \\
\hline 8 & Julio Bueno & Pianista, arreglista \\
\hline 9 & Wilman Palacios Jaramillo & Intérprete, arreglista \\
\hline 10 & Lorena Terán Ludeña & Intérprete \\
\hline 11 & Patricio Jaramillo Carrillo & Director orquesta \\
\hline 12 & César Chauvín & Bajo- intérprete \\
\hline 13 & Verónica,Chauvín & Intérprete \\
\hline 14 & Rafael Minga & Intérprete \\
\hline 15 & Mercedes Placencia Peña & Intérprete \\
\hline 16 & Anita Placencia Peña & Intérprete \\
\hline 17 & José Morocho & Intérprete \\
\hline 18 & María Agusta Abad & Contralto \\
\hline 19 & Judith Abad & Soprano \\
\hline 20 & Manfred,Mora Celi & Concertista \\
\hline 21 & RWolfan Mora Celi & Intérprete \\
\hline 22 & Salvador Zaragocín & Arreglista \\
\hline 23 & Verónica Pardo Frías & Intérprete \\
\hline 24 & Karla Román & Intérprete \\
\hline 25 & Claudia Toro & Intérprete \\
\hline 26 & Ruth Angélica Villamagua & Intérprete \\
\hline 27 & Efrén Rojas Ludeña & Instrumentista \\
\hline 28 & Efrén Rogelio Rojas,Mendieta & Instrumentista \\
\hline 29 & Manuel Rojas Ludeña & Instrumentista \\
\hline 30 & Aleona Galike & Instrumentista \\
\hline 31 & Manuel Andrés Rojas Galike & Instrumentista \\
\hline 32 & Cristian Rojas,Galike & Instrumentista \\
\hline 33 & Lizandro Cabrera & Intérprete \\
\hline 34 & Guillermo Veintimilla & Intérprete \\
\hline 35 & Guillermo Iñiguez & Intérprete \\
\hline 36 & Jaime González & Percusión \\
\hline 37 & Pablo Valarezo & Instrumentista \\
\hline 38 & Elvira Guerrero Macas & Intérprete \\
\hline 39 & Sonia Espinoza & Intérprete \\
\hline 40 & Freddy Jaraillo & Instrumentista \\
\hline 41 & Blonder Mendieta & Instrumentista \\
\hline 42 & Antonio Patiño & Instrumentista \\
\hline 43 & Patricio Castro & Instrumentista \\
\hline 44 & Juan Castro & Instrumentista \\
\hline 45 & Jamil Celi & Instrumentista \\
\hline 46 & Edwin Jumbo & Instrumentista \\
\hline 47 & Andrea Segarra & Instrumentista \\
\hline 48 & Diana Serrano & Instrumentista \\
\hline 49 & María Cristina Neira Rodríguez & Instrumentista \\
\hline 50 & Camila Nicolle Neira Rodríguez & Instrumentista \\
\hline 51 & Diana Severino & Instrumentista \\
\hline 52 & Holger Bustamante & nstrumentista \\
\hline 53 & Julio Mendosa & Instrumentista \\
\hline 54 & Paúl Ruque & Instrumentista \\
\hline 55 & Franklin Ruque & Instrumentista \\
\hline 56 & Fanny Mariana Ortiz & Intérprete \\
\hline 57 & María del Cisne Coronel & Pedagogía musical \\
\hline 58 & Luis Morocho Medina & Director de coro \\
\hline 59 & Gladys Chamba & Intérprete \\
\hline 60 & Elsie Alvarado Román & Instrumentista \\
\hline 61 & Diego Ordoñez & Instrumentista \\
\hline 62 & María Carrión & Instrumentista \\
\hline 63 & Joseph Mendosa & Instrumentista \\
\hline 64 & Marcos Cañar Ramos & Instrumentista \\
\hline 65 & Juan Puglla & Instrumentista \\
\hline 66 & Vicente Morocho & Instrumentista \\
\hline 67 & Ángel Lozano & Instrumentista \\
\hline 68 & Ángel Ortega Gutiérrez & Instrumentista \\
\hline 69 & Fanny Ruque & Instrumentista \\
\hline 70 & Piero Guzmán & Instrumentista \\
\hline 71 & Abel Guzmán & Instrumentista \\
\hline 72 & María Dolores Macas & Instrumentista \\
\hline 73 & Beatriz Morales Benavides & Instrumentista \\
\hline 74 & Jorge Salinas & Instrumentista \\
\hline 75 & Emilio Salinas & Instrumentista \\
\hline 76 & Elvis Tapia & Instrumentista \\
\hline 77 & Gabriela Pacají & Instrumentista \\
\hline 78 & Darío Cobos & Instrumentista \\
\hline 79 & Fabricio Toro & Instrumentista \\
\hline
\end{tabular}

Fuente: Secretaría Conservatorio de Música Salvador Bustamante Celi. 
Tabla 4. Cantidad de música que se genera en Loja

\begin{tabular}{|c|c|c|c|c|c|c|c|}
\hline $\begin{array}{c}\text { Estudios } \\
\text { de } \\
\text { grabación }\end{array}$ & $\begin{array}{c}\text { No } \\
\text { grabaciones } \\
\text { Mensuales }\end{array}$ & $\begin{array}{c}\mathrm{N}^{\mathbf{0}} \\
\text { grabaciones } \\
\text { Anuales }\end{array}$ & $\begin{array}{c}\text { Personalidades } \\
\text { musicales }\end{array}$ & $\begin{array}{c}\mathrm{N}^{\circ} \\
\text { grabaciones } \\
\text { Anuales }\end{array}$ & $\begin{array}{l}\text { Museo } \\
\text { de la } \\
\text { música }\end{array}$ & Sayce & IEPI \\
\hline Chavi Records & 100 & 1200 & \multirow{6}{*}{840} & \multirow{6}{*}{10080} & \multirow{6}{*}{$\begin{array}{l}\text { Música } \\
\text { conservada } \\
\text { en el } \\
\text { repositorio }\end{array}$} & \multirow{6}{*}{$\begin{array}{l}\text { Producción } \\
\text { musical anual } \\
\text { registrada en } \\
\text { Loja }\end{array}$} & \multirow{6}{*}{$\begin{array}{c}\text { Cantidad } \\
\text { de música } \\
\text { registrada del } \\
2000 \text { al } 2016\end{array}$} \\
\hline Wilman Palacios & 80 & 960 & & & & & \\
\hline Boris Eguiguren & 50 & 600 & & & & & \\
\hline Lozano & 70 & 840 & & & & & \\
\hline Roque Pineda & 60 & 720 & & & & & \\
\hline Otros & 80 & 960 & & & & & \\
\hline TOTAL & 440 & 5,280 & 840 & 10,080 & 1,000 & 18,000 & 20,000 \\
\hline
\end{tabular}

Fuente: Estudios de grabación de Loja, Sayce, Museo de la música, IEPI.

Tabla 5. Estudiantes del Conservatorio Salvador Bustamente Celi de Loja.

\begin{tabular}{|l|c|c|c|}
\hline \multicolumn{1}{|c|}{ Niveles de Formación } & Ingreso & Egreso & Graduados \\
\hline $\begin{array}{l}\text { Formación Básica } \\
\text { Inicial (2 años lectivos) }\end{array}$ & 8,320 & 2,343 & 1,420 \\
\hline $\begin{array}{l}\text { Formación Básica } \\
\text { (8 años) }\end{array}$ & 5,373 & 1,840 & 927 \\
\hline $\begin{array}{l}\text { Formación de Bachillerato } \\
\text { (3 años) }\end{array}$ & 945 & 989 & 841 \\
\hline TOTAL & $\mathbf{1 4 , 6 3 8}$ & $\mathbf{5 , 1 7 2}$ & $\mathbf{3 , 1 8 8}$ \\
\hline
\end{tabular}

Fuente: Conservatorio de Música S.B.C.

Tabla 6. Estudiantes del Conservatorio Antón Bruckner, 2000 - 2016.

\begin{tabular}{|l|c|c|c|}
\hline \multicolumn{1}{|c|}{ Niveles de Formación } & Ingreso & Egreso & Graduados \\
\hline $\begin{array}{l}\text { Formación Básica } \\
\text { Inicial (2 años lectivos) }\end{array}$ & 3,278 & 246 & 190 \\
\hline $\begin{array}{l}\text { Formación Básica } \\
(8 \text { años) }\end{array}$ & 2,144 & 185 & 121 \\
\hline $\begin{array}{l}\text { Formación de Bachillerato } \\
\text { (3 años) }\end{array}$ & 1,001 & 23 & 23 \\
\hline TOTAL & $\mathbf{6 , 4 2 3}$ & $\mathbf{4 5 4}$ & $\mathbf{3 3 4}$ \\
\hline
\end{tabular}

Fuente: Conservatorio Antón Bruckner.

Tabla 7. Ingreso de estudiantes de la carrera de Educación Musical de la UNL, 2010 - 2016.

\begin{tabular}{|l|l|l|l|l|l|l|l|l|}
\hline Ciclos de Formación & $\mathbf{2 0 1 0}$ & $\mathbf{2 0 1 1}$ & $\mathbf{2 0 1 2}$ & $\mathbf{2 0 1 3}$ & $\mathbf{2 0 1 4}$ & $\mathbf{2 0 1 5}$ & $\mathbf{2 0 1 6}$ & \\
\hline Ciclo 1 & 34 & 24 & 17 & 14 & 26 & 12 & 12 & 139 \\
\hline Ciclo 2 & 21 & 17 & 14 & 13 & 22 & 8 & & 95 \\
\hline Ciclo 3 & 20 & 16 & 13 & 13 & 20 & 8 & & 90 \\
\hline Ciclo 4 & 18 & 14 & 12 & 12 & 20 & 8 & & 84 \\
\hline Ciclo 5 & 16 & 12 & 10 & 12 & 18 & & & 68 \\
\hline Ciclo 6 & 15 & 10 & 10 & 12 & 17 & & & 64 \\
\hline Ciclo 7 & 12 & 10 & 8 & 11 & 14 & & & 55 \\
\hline Ciclo 8 & 7 & 9 & 8 & 11 & 9 & & & 44 \\
\hline Subtotal & 143 & 112 & 92 & 98 & 146 & 16 & 12 & 619 \\
\hline $\begin{array}{l}\text { Subtotal } \\
\text { educadores } \\
\text { musicales }\end{array}$ & & & & & & & \\
\hline $\begin{array}{l}\text { Subtotal } \\
\text { instrumentistas }\end{array}$ & & & & & & & & \\
\hline TOTAL & 143 & 112 & 92 & 98 & 146 & 16 & 12 & 619 \\
\hline Media aritmética & 12 & & & & & & & \\
\hline Tasa de crecimiento & $-21 \%$ & & & & & & & \\
\hline
\end{tabular}

Fuente: Carrera de Educación Musical UNL. 